\title{
APPLICATION OF RESPONSE SURFACE METHODOLOGY FOR \\ OBTAINING LETTUCE (Lactuca sativa L.) BY-PRODUCTS EXTRACTS WITH HIGH ANTIOXIDATIVE PROPERTIES
}

Teresa Gomes $^{\mathrm{a}}$, Teresa Delgado ${ }^{\mathrm{a}, \mathrm{b}}$, Anabela Ferreira ${ }^{\mathrm{a}}$, José Alberto Pereira ${ }^{\mathrm{a}}$, Paula Baptista $^{\mathrm{a}}$, Susana Casal ${ }^{\mathrm{b}}$ and Elsa Ramalhosa ${ }^{\mathrm{a}^{*}}$

${ }^{a}$ Mountain Research Centre (CIMO) - School of Agriculture, Polytechnic Institute of Bragança, Campus de St Apolónia, Apartado 1172, 5301-855 Bragança, Portugal ${ }^{b}$ REQUIMTE/Laboratory of Bromatology and Hydrology, Faculty of Pharmacy, Porto University, Rua Jorge Viterbo Ferreira, 228, 4050-313 Porto, Portugal

*To whom correspondence should be addressed. Telephone: +351-273-303308. Fax: +351-273-325405. E-mail: elsa@ipb.pt 


\section{AbSTRACT}

The main objective of the present work was to optimize the extraction conditions for simultaneous maximization of total reducing (TRC) and antioxidant (AC) capacities for lettuce (Lactuca sativa L.) by-products extracts, using response surface methodology. For this, a design of experiments (DOE) with different combinations of solvents (water, methanol and acetone) extraction temperatures $\left(30-60^{\circ} \mathrm{C}\right)$ and time $(10-60 \mathrm{~min})$ on the TRC and AC was applied. Higher and consistent fittings using second order polynomial models of the experimental data with regard to TRC $\left(\mathrm{R}^{2}=0.529\right.$, $\left.\mathrm{p}_{\text {lack of fit }}>0.05\right)$ and $\mathrm{AC}$ $\left(\mathrm{R}^{2}=0.900, \mathrm{p}_{\text {lack of }} \mathrm{fit}>0.05\right)$ were obtained with methanol. The optimum extraction conditions based on combination responses for TRC and AC were: $30 \%$ methanol $(\mathrm{v} / \mathrm{v}), 60^{\circ} \mathrm{C}$ and $60 \mathrm{~min}$. A close agreement between experimental and predicted values was found when applying these conditions. Furthermore, when aqueous extracts were prepared (e.g. $45^{\circ} \mathrm{C}, 10 \mathrm{~min}$ ), these presented similar TRC and AC properties to those obtained by the above optimum extraction conditions, having the advantage of applying mild extraction conditions and avoiding the use of organic solvents in their preparation.

Keywords: Lettuce; Response Surface Methodology; Extraction optimization; Total Reducing Capacity; Antioxidant Capacity. 


\section{Introduction}

Lettuce (Lactuca sativa) is one of the most consumed vegetables in many parts of the world. Its worldwide production reaches 21 million metric tons, of which Portugal contributes with 95 thousand metric tons, ranking fifteen in FAO producing statistics (FAO, 2005). Generally sold as whole, fresh-cut lettuce products had a great development due to the recent demand for ready-to-eat vegetables, in line with an increasing awareness for its bioactive properties, particularly regarding antioxidant activity. However, these products leave the industrials that deal with lettuce production/transformation with a large amount of residues and wastes (ex. leaves, stems, etc.), reaching up to $50 \%$ of the harvested material (Llorach et al., 2004). In order to avoid environmental and hygienic problems associated with their disposal or inadequate use, the valorization of these byproducts is crucial.

Some studies have demonstrated that lettuce byproducts could be an interesting and cheap source of natural antioxidants used, for instance, to functionalize foods (Llorach et al., 2004). Reports on the antioxidative effect of lettuce extracts are widespread in the literature (Altunkaya et al., 2009; Altunkaya and Gökmen, 2008). Knowing that secondary metabolism and antioxidants are an integral part of plant adaptation to environmental perturbations that occur under normal growing conditions (Oh et al., 2009), most studies focus on how antioxidant activity varies under different conditions. Biofortification with selenium (Ríos et al., 2008; Ramos et al., 2010), the application of exogenous abscisic acid (Li et al., 2010) and the effect of temperature (Boo et al., 2011) on lettuce growth and antioxidants production are subjects studied until now. Recently, Ozgen and Sekerci (2011) stated that the outer leaves in both red and green color lettuce exhibited significantly higher total phenolics and antioxidant capacity than middle and inner leaves. As these outer leaves are frequently rejected during ready-to-eat vegetables 
processing, this observation is of particular importance. The increased phenolic content and antioxidant capacity of lettuce leaf tissues after wounding (Kang and Saltveit, 2002) is also interesting regarding fresh-cut lettuce products and residues.

Total phenols and antioxidant activity is usually determined on liquid extracts, obtained under several conditions: i) Methanol (Ríos et al., 2008) under continuous stirring for 1 h (Chisari et al., 2010) or for $30 \mathrm{~s}$ (Kang and Saltveit, 2002) at room temperature, or under reflux for $1 \mathrm{~h}$ (Llorach et al., 2004); ii) Water under reflux for $1 \mathrm{~h}$ (Llorach et al., 2004), for 6 or $24 \mathrm{~h}$ at room temperature (Altunkaya et al., 2009; Altunkaya and Gökmen, 2008) or for $10 \mathrm{~min}$ at $80{ }^{\circ} \mathrm{C}$ (Altunkaya et al., 2009); iii) Methanol:water:acetic acid $(85: 15: 0.5, \mathrm{v} / \mathrm{v})$ by sonication for $5 \mathrm{~min}$ and kept at room temperature for 20 min (Boo et al., 2011; Li et al., 2010); iv) Sodium phosphate (pH 7.5) for $1 \mathrm{~min}$ followed by ethyl acetate (Cano and Arnao, 2005); and $v$ ) Acetone:water:acetic acid (70:29.5:0.5, v/v) for $24 \mathrm{~h}$ at $4{ }^{\circ} \mathrm{C}($ Ozgen and Sekerci, 2011). The extraction solvents determine the type of compounds extracted, while solvent ratio, temperature, and extraction time influence the extraction yield and stability of the compounds in the solution, globally responsible for different results over chemical assays regarding both total phenols compounds and antioxidant activity. In order to obtain reproducible results, comparable over different working teams and matrices, the extraction conditions should be optimized and maximized. Response Surface Methodology (RSM) is a useful methodology for this optimization, allowing the evaluation of multiple factors and of their interactions over one or more response variables. The most popular form of RSM is the Central Composite Design and has been used in several studies to optimize the conditions of extraction of many compounds (Ballard et al., 2009; Cheok et al., 2012; Khan et al., 2010; Vázquez et al., 2012). 
The aim of this work was to evaluate the role of the extraction conditions, namely, solvent type, temperature, and time, on the total reducing and antioxidant capacities of lettuce by-products extracts by RSM for their possible use as food or pharmaceutical antioxidants.

\section{Material and methods}

\subsection{Plant material}

A commercial variety of lettuce (Lactuca sativa) with flat green leaf was used in the present work. Upon arrival to the laboratory, the outer leaves of the lettuces, usually discarded by consumers, were carefully rinsed with ultra-pure water, and the excess of water removed by soft paper. Leaves were dried at $60^{\circ} \mathrm{C}$ for $24 \mathrm{~h}$ and ground into fine powder using a blender. Weight loss was recorded in order to express the results on a fresh basis. In a previous work (Ferreira, 2011) it was observed that drying lettuce under these conditions did not cause loss of phenols compounds. The lettuce used had a water content of $96-97 \%$

\subsection{Chemicals and reagents}

Methanol and acetone were obtained from Carlo Erba Reagents Group and SigmaAldrich, respectively. Gallic acid and DPPH (2,2-diphenyl-1-picrylhydrazyl) were from Sigma-Aldrich while Folin-Ciocalteu reagent and sodium carbonate were obtained from Panreac Quimica SA. All reagents were of analytical grade. Milli-Q system (Millipore Corp., Bedford, MA) ultrapure water was used throughout this research.

\subsection{Extraction conditions}


Dried powder $(1 \mathrm{~g})$ of lettuce was extracted with $25 \mathrm{~mL}$ of different solvent at 30, 45 or $60{ }^{\circ} \mathrm{C}$ for 10,35 or 60 minutes, under stirring. The solvents used in the present work were methanol/water $(30,60$ or $90 \%(\mathrm{v} / \mathrm{v})$, acetone/water $(30,60$ or $90 \%(\mathrm{v} / \mathrm{v})$ and water. Each solvent extraction was carried out in triplicate. The flasks were wrapped in aluminum foil to prevent light degradation during extraction. After cooling, the extracts were filtered and stored at $-18{ }^{\circ} \mathrm{C}$. In a previous work (Ferreira, 2011) it was stated that this buffer-to-solids ratio was adequate for compounds extraction with total reducing and antioxidant capacities from the dried sample.

\subsection{Total Reducing Capacity (TRC)}

TRC of lettuce extracts was determined according to the colorimetric Folin-Ciocalteu method, as described by Singleton and Rossi (1965). Briefly, the extract solution was mixed with Folin Ciocalteu reagent and saturated $\mathrm{Na}_{2} \mathrm{CO}_{3}$ solution (1 ml each), left to react for 3 minutes and fulfill with ultrapure water up to the $10 \mathrm{~mL}$ mark. The reaction was kept in the dark during 90 minutes and then the absorbance was read at $725 \mathrm{~nm}$ (Thermo Electron Corporation Genesys $10 \mathrm{UV}$-Vis spectrophometer). Simultaneously, several gallic acid solutions $(0.01$ to $0.4 \mathrm{mmol} / \mathrm{L})$ were prepared and subjected to the same methodology in order to obtain a calibration curve. The results were expressed as mg gallic acid equivalent (GAE)/g fresh weight.

\subsection{Antioxidant capacity by DPPH (2,2-diphenyl-1-picrylhydrazyl)}

The free radical scavenging activity was determined according to the method described by Hatano et al. (1988). A $0.3 \mathrm{~mL}$ accurate amount of extract solution was added to a DPPH radicals solution $\left(2.7 \mathrm{~mL}, 6 \times 10^{-5} \mathrm{~mol} / \mathrm{L}\right)$. After mixing, the solution was kept in the dark during 60 minutes. The absorbance was determined at $517 \mathrm{~nm}$ (Thermo Electro 
Corporation Genesys 10 UV-vis Spectrophotometer). Simultaneously, a control was prepared by substituting the extract by the solvent. The free radical scavenging effect was evaluated using the following equation:

$$
\text { DPPH scavenging activity }(\%)=\left[\left(A_{D P P H}-A_{S}\right) / A_{D P P H}\right] \times 100
$$

where $A_{D P P H}$ was the absorbance of the control reaction and $A_{S}$ the absorbance in the presence of the sample extract.

\subsection{Experimental design and statistical analysis}

In order to determine the best extraction conditions to optimize TRC and DPPH scavenging effect of lettuce extracts, the Response Surface Methodology (RSM) of Minitab software was used. For methanol and acetone extractions a one block facecentered $(\alpha=1)$ central composite design (CCD) was constructed to investigate the influence of extraction conditions. Three independent factors were considered: solvent $\%\left(X_{1}: 30\right.$ to $\left.90 \%(\mathrm{v} / \mathrm{v})\right)$, temperature $\left(X_{2}: 30\right.$ to $\left.60{ }^{\circ} \mathrm{C}\right)$ and time $\left(X_{3}: 10\right.$ to $\left.60 \mathrm{~min}\right)$. For water a two-factor design was used because the effect of solvent concentration was not applicable. The response variables were TRC and DPPH scavenging effect. Each variable to be optimized was coded at three levels: $-1,0,+1$. The correspondence between coded and uncoded variables is indicated in Table 1. Each point of the CCD was carried out in triplicate.

The relationship found between the dependent variables (TRC and DPPH scavenging effect) and the operational variables was established by the following second order polynomial model:

$$
Y=\beta_{0}+\sum_{i=1}^{k} \beta_{i} X_{i}+\sum_{i=1}^{k} \beta_{i i} X_{i}^{2}+\sum_{i>j}^{k} \beta_{i j} X_{i} X_{j}
$$


where $Y$ is the predicted dependent variable; $\beta_{0}$ is a constant that fixes the response at the central point of the experiment (intercept); $\beta_{i}$ are the regression coefficients for the linear effect terms; $\beta_{i i}$ are the quadratic effect terms; $\beta_{i j}$ are the interaction effect terms of variables $i$ and $j ; X_{i}$ and $X_{j}$ are independent variables, and $k$ the total number of independent factors.

In the experiments involving methanol and acetone (Table 2), 20 experiments with six replications in the central point (Experiments 1, 5, 14, 15, 19 and 20) were performed. In the case of water (Table 3), 13 experiments with five replications in the central point were done because only two factors were tested: time and temperature. In order to limit the influence of systematic errors, the sequence of the experiments was randomly established. The experiments performed in the central point allowed to estimate the influence of the experimental error, whereas the other experiments allowed the calculation of the regression coefficients of the model. The adequacy of the models was predicted through the determination coefficient $\left(R^{2}\right)$ and analysis of variance (ANOVA).

\section{Results and Discussion}

\subsection{Total Reducing and Antioxidant Capacities}

The TRC and DPPH scavenging effect determined for methanol, acetone and water experiments are shown in Tables 2 and 3. Differences between solvents and extraction conditions were observed. For TRC, the methanol extracts ranged between 0.269 and $0.566 \mathrm{mg} \mathrm{GAE} / \mathrm{g}$ fresh weight, whereas for acetone it ranged between 0.246 and 0.669 mg GAE/g fresh weight, both lower than the range observed with aqueous extraction where TRC ranged between 0.337 and $0.741 \mathrm{mg} \mathrm{GAE} / \mathrm{g}$ fresh weight. Our results are of the same order of magnitude to those reported by Ozgen and Sekerci (2011) for outer leaves of Krizet and Freckles varieties (both green cultivars), $0.214-0.431 \mathrm{mg} \mathrm{GAE} / \mathrm{g}$ 
fresh weight, when using acetone, water and acetic acid (70:29.5:0.5 v/v) at $4{ }^{\circ} \mathrm{C}$ for 24 hours. On contrary, higher total phenol concentrations were determined in the present work when compared to Cano and Arnao (2005) for the outermost leaves of Baby head and Romaine varieties after performing aqueous extractions with $50 \mathrm{mM}$ sodium phosphate $(0.026-0.085 \mathrm{mg}$ GAE/g fresh weight). This may be due to the lower extraction time (aprox. 1 minute) applied by those authors.

Regarding DPPH scavenging effect, differences between extraction conditions and solvents were also detected. The highest variations were determined with acetone, with values ranging between $10.4-89.8 \%$, while with methanol and water the values ranged between $51.4-90.8 \%$ and $63.2-89.4 \%$, respectively.

In relation to extraction conditions, the highest values of TRC were obtained at $60{ }^{\circ} \mathrm{C}$ for 10 minutes with methanol $30 \%(\mathrm{v} / \mathrm{v})$ or acetone $30 \%(\mathrm{v} / \mathrm{v})($ Experiment 2 for both solvents), or water at $45{ }^{\circ} \mathrm{C}$ for 35 minutes (Experiment 6). For the antioxidant activity, the highest DPPH scavenging effects were obtained at $60{ }^{\circ} \mathrm{C}$ for 60 minutes with methanol $30 \%(\mathrm{v} / \mathrm{v})$ (Experiment 18), at $45{ }^{\circ} \mathrm{C}$ for 35 minutes with acetone $60 \%(\mathrm{v} / \mathrm{v})$ and water at $45{ }^{\circ} \mathrm{C}$ for 35 minutes.

\subsection{Response Surface Modeling}

The fitted quadratic models parameters for TRC and DPPH scavenging effect are presented in Table 4. The significance level of each coefficient was determined using the $p$-value (Table 4). The most significant variables were those that presented the lower values for this statistic parameter $(p<0.05)$. To check the quality of the models the determination coefficient $\left(R^{2}\right)$ and the lack of fit were also evaluated (Table 4). A good

fit was obtained when there is a high $R^{2}$ and a $p$-value for the lack of fit higher than 
0.05 , indicating that the variation between samples was due only to the factors selected for the model and the pure error (Puértolas et al., 2011).

\subsubsection{TRC Models}

For methanol extractions, only the interaction term of solvent concentration and temperature $\left(X_{1} X_{2}\right)$ had significant effect $(p<0.05)$ on TRC (Table 4$)$. On the other hand, time $\left(X_{3}\right)$ did not show any significant contribution to this parameter. The determination coefficient and $p$-value for lack of fit of the predicted model were 0.529 and 0.574 , respectively, which suggest that the fitted model can reasonably represent the observed values. Some similarities were observed between the experimental values and those predicted by the model (Table 2). The contour plot and 3D response surfaces of TRC for methanol are shown in Fig. $1 \mathrm{~A}$ and $1 \mathrm{~B}$ and demonstrated that the region of low methanol concentrations $(30-40 \%, \mathrm{v} / \mathrm{v})$ and high temperatures $\left(>45{ }^{\circ} \mathrm{C}\right)$ would give higher TRC (Fig. 1A). The insignificant role of the extraction time on TRC could be observed from Fig. 1B as TRC did not change with time for a given temperature. Extended times are expected to favor the extraction of polyphenolic compounds and so the TRC, since it takes time to the fluid to penetrate into the dried product, dissolve the solute and subsequently diffuse out to the extraction medium (Gan and Latiff, 2011). However, in this study this variable had no significant effect. In opposition, the use of higher temperatures seemed to increase the TRC. As mentioned by Ju and Howard (2003) and Shi et al. (2003) the use of higher temperatures may cause softening of plant tissue, disruption of the interactions between phenolic compounds and protein or polysaccharides, increasing phenolic solubility, and reducing solvent viscosity and surface tension, which enhances the diffusion rate, thus giving a higher extraction rate. This effect is known to be limited, as temperatures higher than $60{ }^{\circ} \mathrm{C}$ might induce 
degradation of the extracted phenolic compounds, with opposing effects on the TRC results.

Regarding acetone extractions, solvent concentration, temperature and time showed no significant contribution to TRC $(p>0.05)$ (Table 4), indicating that probably other factors affecting this property exist. The use of high acetone concentrations on the extraction medium coupled with high temperatures and long extraction times may cause solvent evaporation and consequently some variability. In terms of water extractions, temperature and extraction time did not show any significant contribution to TRC $(p>0.05)$, causing a fitted model with a low $R^{2}(0.382)$ (Table 4). As no significant effects were obtained with these two solvents, the contour plot and 3D response surfaces for TRC were not shown.

\subsubsection{Antioxidant capacity - DPPH scavenging effect}

In terms of antioxidant activity of methanol and acetone extracts, the linear term of solvent concentration $\left(X_{1}\right)$ and temperature $\left(X_{2}\right)$, the quadratic term of solvent concentration $\left(X_{I}^{2}\right)$, and the interaction terms of solvent concentration and temperature $\left(X_{1} X_{2}\right)$, as well as temperature and extraction time $\left(X_{2} X_{3}\right)$, had significant roles $(p<0.05)$ on DPPH scavenging effect. For acetone the quadratic term of temperature $\left(X_{2}^{2}\right)$ also contributed significantly to the antioxidant activity. Good coefficients of determination of the predicted models were obtained, namely, 0.900 and 0.969 for methanol and acetone, respectively. However, only for methanol a $p$-value $>0.05(0.181)$ for lack of fit was obtained, suggesting a good fit to the mathematical model (Eq. 3).

$\mathrm{DPPH}_{\mathrm{Met}}=87.32-5.01 X_{1}+8.52 X_{2}-9.10 X_{1}^{2}+6.38 X_{1} X_{2}+4.05 X_{2} X_{3}$ 
On the other hand, for acetone the $p$-value for lack of fit was $<0.001$ which suggested that the model developed (Eq. 4) can only reasonably represent the observed results.

$$
\mathrm{DPPH}_{\text {Ace }}=88.78-19.66 X_{1}+9.91 X_{2}-18.84 X_{1}^{2}-10.43 X_{2}^{2}+7.32 X_{1} X_{2}+4.49 X_{2} X_{3}
$$

Nevertheless, when comparing the experimental values and those predicted by the models (Table 2), many similarities were observed. Thus, the contour plot and 3D response surfaces of DPPH scavenging effect for methanol and acetone are shown in Fig. 2 and 3. Lower inhibition percentages were obtained with high methanol concentrations and low temperatures (around $30^{\circ} \mathrm{C}$ ) (Fig. 2A), supported by the knowledge that a combination of alcohol with water is more effective in extracting phenolic compounds than alcohol alone (Markom et al., 2007). It was also stated that an extraction temperature up to $60{ }^{\circ} \mathrm{C}$ did not cause degradation of antioxidants with DPPH scavenging effect. Concerning extraction time (Fig. 3A), the lower antioxidant activities were obtained when low temperatures $\left(30^{\circ} \mathrm{C}\right)$ and high extraction times were used. Regarding acetone (Fig. 2B), the lower DPPH scavenging effects were observed again for high solvent concentrations $(>70 \%, \mathrm{v} / \mathrm{v})$. It appeared that the reduction of DPPH scavenging effect was even more pronounced for higher solvent percentages than in the case of methanol. However, similar results were obtained for both solvents. When using acetone $30 \%(\mathrm{v} / \mathrm{v})$ (Fig. 3B), the results showed that the region of $40-50{ }^{\circ} \mathrm{C}$ would give higher DPPH scavenging effects, independently time extraction. It is important to refer that the 3D plots for both solvents (Fig. 3) were only shown at -1 level of solvent concentration (i.e., $30 \%, \mathrm{v} / \mathrm{v}$ ) because the highest DPPH scavenging effects were obtained with low solvent concentrations as stated previously. 
For water extractions, temperature and extraction time did not again show any significant contribution to DPPH scavenging effect $(p>0.05)$. Even though the lack of fit was non-significant $(\mathrm{p}>0.05)$, the fitted model presented a low $R^{2}(0.136)$ (Table 4$)$. This indicated that the developed model may not provide the experimental values as desired. As no good results were obtained with this solvent, the contour plot and 3D response surfaces of DPPH scavenging effect were not shown.

\subsection{Optimization of Total Reducing and Antioxidant Capacities and Models Verification}

To evaluate the extraction conditions that optimized the responses of TRC and DPPH scavenging effect, an optimization study was performed using the "Response Optimizer" option of Minitab ${ }^{\star}$ software. Our target was to obtain simultaneously high TRCs and high DPPH scavenging effects. For methanol, the solvent concentration and temperature were the factors that most influenced the TRC and DPPH scavenging effect, and the experimental conditions that simultaneously optimized both responses were determined. In Fig. 4A it is represented the zone (white area) where a TRC between 0.35 and $0.56 \mathrm{mg}$ GAE/g fresh weight and a DPPH scavenging effect between 80 and $90 \%$ were obtained simultaneously. The optimal extraction conditions determined for methanol were equal to $30 \%(\mathrm{v} / \mathrm{v}), 60{ }^{\circ} \mathrm{C}$ and 60 minutes. When these conditions were applied, a TRC equal to $0.445 \pm 0.004 \mathrm{mg} \mathrm{GAE} / \mathrm{g}$ fresh weight and a DPPH scavenging effect of $82.8 \pm 0.7 \%$ were obtained, showing that these results were within the range defined in the optimization for both parameters.

Regarding acetone, the solvent concentration and temperature were also the most significant factors. In Figure $4 \mathrm{~B}$ it is represented the zone (white area) that allowed to obtain at the same time a TRC between 0.40 and $0.65 \mathrm{mg} \mathrm{GAE} / \mathrm{g}$ fresh weight and a DPPH scavenging effect between 80 and $90 \%$. The optimum extraction conditions 
obtained for acetone were equal to $30 \%(\mathrm{v} / \mathrm{v}), 43{ }^{\circ} \mathrm{C}$ and 10 minutes. When applying these conditions, a TRC of $0.378 \pm 0.002 \mathrm{mg}$ GAE/g fresh weight and a DPPH scavenging effect equal to $83.5 \pm 0.7 \%$ were obtained. Although the value of TRC was slightly lower than the range established for optimization, the results for DPPH scavenging effect were in accordance with the range defined. As stated before, the fitted model developed for the TRC for acetone $\left(R^{2}=0.364\right)$ was not as good as the one determined for DPPH scavenging effect $\left(R^{2}=0.969\right)$, explaining this slight difference on TRC value. Nevertheless, for both solvents the optimum extraction conditions determined gave similar TRCs and DPPH scavenging effects. In case of water the optimum extraction conditions were not determined once temperature and time were factors without significance for both properties. However, when observing Table 3, some aqueous extracts (e.g. $45^{\circ} \mathrm{C}, 10 \mathrm{~min}$ ) presented similar TRC and $\mathrm{AC}$ properties to those when the above optimum extraction conditions were applied, having the advantage of applying mild extraction conditions and avoiding the use of organic solvents in their preparation.

\section{Conclusions}

RSM was successfully used to determine the optimum extraction conditions that simultaneously yield high total reducing and antioxidant capacities in lettuce extracts. ANOVA showed that the solvent concentration and temperature were significant factors to TRC only for methanol, whereas none of the three factors studied (solvent concentration, temperature, time) was significant for acetone and water extractions. On the other hand, these three factors played an important role on DPPH scavenging capacity for both methanol and acetone. Some quadratic models developed in the present work could be used to successfully predict the experimental data, being the best 
results obtained with methanol. In order to produce lettuce extracts with simultaneously high TRC and DPPH scavenging effect, methanol $30 \%(\mathrm{v} / \mathrm{v})$ at $60{ }^{\circ} \mathrm{C}$ for $60 \mathrm{~min}$ should be employed. Lettuce extracts with TRC and DPPH scavenging effect equal to $0.445 \pm 0.004 \mathrm{mg} \mathrm{GAE} / \mathrm{g}$ fresh weight and $82.8 \pm 0.7 \%$, respectively, were obtained. However, some aqueous extracts (e.g. $45^{\circ} \mathrm{C}, 10 \mathrm{~min}$ ) presented similar TRC and AC properties. In this way, mild extraction conditions may be applied and the use of organic solvents is avoided. 


\section{Acknowledgements}

We acknowledge FCT (Fundação para a Ciência e Tecnologia) and FEDER through the COMPETE program under the projects FCOMP-01-0124-FEDER-008703 (FCT/PTDC/AGR-AAM/102447/2008), PEst-C/EQB/LA0006/2011, and PEstOE/AGR/UI0690/2011.

\section{References}

Altunkaya, A., Gökmen, V., 2008. Effect of various inhibitors on enzymatic browning, antioxidant activity and total phenol content of fresh lettuce (Lactuca sativa). Food Chem. 107, 1173-1179.

Altunkaya, A., Becker, E.M., Gökmen, V., Skibsted, L.H., 2009. Antioxidant activity of lettuce extract (Lactuca sativa) and synergism with added phenolic antioxidants. Food Chem. 115, 163-168.

Ballard, T.S., Mallikarjunan, P., Zhou, K., O’Keefe, S.F., 2009. Optimizing extraction of phenolic antioxidants from peanut skins using response surface methodology. J. Agric. Food. Chem. 57, 3064-3072.

Boo, H.-O., Heo, B.-G., Gorinstein, S., Chon, S.-U., 2011. Positive effects of temperature and growth conditions on enzymatic and antioxidant status in lettuce plants. Plant Sci. 181, 479-484.

Cano, A., Arnao, M.B., 2005. Hydrophilic and lipophilic antioxidant activity in different leaves of three lettuce varieties. Int. J. Food Prop. 8, 521-528. 
Cheok, C.Y., Chin, N.L., Yusof, Y.A., Talib, R.A., Law, C.L., 2012. Optimization of total phenolic content extracted from Garcinia mangostana Linn. hull using response surface methodology versus artificial neural network. Ind. Crops Prod. 40, 247-253.

Chisari, M., Todaro, A., Barbagallo, R.N., Spagna, G., 2010. Salinity effects on enzymatic browning and antioxidant capacity of fresh-cut baby Romaine lettuce (Lactuca sativa L. cv. Duende). Food Chem. 119, 1502-1506.

FAO (2005). FAOSTAT database (http://www.fao.org/es/ess/top/commodity.html) (Accessed on: 20 ${ }^{\text {th }}$ June 2012)

Ferreira, A. (2011), Influence of spent coffee grounds on growth and chemical and biological properties of lettuce (Lactuca sativa L.), Master Thesis, School of Agriculture, Polytechnic Institute of Bragança, Portugal.

Gan, C.Y., Latiff, A.A., 2011. Optimization of the solvent extraction of bioactive compounds from Parkia speciosa pod using response surface methodology. Food Chem. 124, 1277-1283.

Hatano, T., Kagawa, H., Yasuhara, T., Okuda, T., 1988. Two new flavonoids and other constituents in licorice root: their relative astringency and radical scavenging effects. Chem. Pharm. Bull. 36, 1090-2097. 
Ju, Z.Y., Howard, L.R., 2003. Effects of solvent and temperature on pressurized liquid extraction of anthocyanins and total phenolics from dried red grape skin. J. Agric. Food. Chem. 51, 5207-5213.

Kang, H.-M., Saltveit, M.E., 2002. Antioxidant capacity of lettuce leaf tissue increases after wounding. J. Agric. Food. Chem. 50, 7536-7541.

Khan, M.K., Abert-Vian, M., Fabiano-Tixier, A.-S., Dangles, O., Chemat, F., 2010. Ultrasound-assisted extraction of polyphenols (flavanone glycosides) from orange (Citrus sinensis L.) peel. Food Chem. 119, 851-858.

Li, Z., Zhao, X., Sandhu, A.K., Gu L., 2010. Effects of exogenous abscisic acid on yield, antioxidant capacities, and phytochemical contents of greenhouse grown lettuces. J. Agric. Food. Chem. 58, 6503-6509.

Llorach, R., Tomás-Barberán, F.A., Ferreres F., 2004. Lettuce and chicory byproducts as a source of antioxidant phenolic extracts. J. Agric. Food. Chem. 52, 5109-5116.

Markom, M., Hasan, M., Daud, W.R.W., Singh, H., Jahim, J.M., 2007. Extraction of hydrolysable tannins from Phyllanthus niruri Linn.: Effects of solvents and extraction methods. Sep. Purif. Technol. 52, 487-496.

Oh, M.-M., Trick H.N., Rajashekar, C.B., 2009. Secondary metabolism and antioxidants are involved in environmental adaptation and stress tolerance in lettuce. J. Plant Physiol. 166, 180-191. 
Ozgen S., Sekerci S., 2011. Effect of leaf position on the distribution of phytochemicals and antioxidant capacity among green and red lettuce cultivars. Span. J. Agric. Res. 9, 801-809.

Puértolas E., Saldaña G., Álvarez I., Raso J., 2011. Experimental design approach for the evaluation of anthocyanin content of rosé wines obtained by pulsed electric fields. Influence of temperature and time of maceration. Food Chem. 126, 1482-1487.

Ramos, S.J., Faquin, V., Guilherme, L.R.G., Castro, E.M., Ávila, F.W., Carvalho, G.S., Bastos, C.E.A., Oliveira, C., 2010. Selenium biofortification and antioxidant activity in lettuce plants fed with selenate and selenite. Plant Soil Environ. 56, 584-588.

Ríos, J.J., Rosales, M.A., Blasco, B., Cervilla, L.M., Romero, L., Ruiz, J.M., 2008. Biofortification of Se and induction of the antioxidant capacity in lettuce plants. Sci. Hortic. 116, 248-255.

Shi, J., Yu, J., Pohorly, J., Young, J.C., Bryan, M., Wu, Y., 2003. Optimization of the extraction of polyphenols from grape seed meal by aqueous ethanol solution. Food, Agriculture \& Environment. 1, 42-47.

Singleton, V.L., Rossi, J.A., 1965. Colorimetry of total phenolics with phosphomolybdic-phosphotungstic acid reagents. Am. J. Enol. Vitic. 16, 144-158. 
Vázquez, G., Fernández-Agulló, A., Gómez-Castro, C., Freire, M.S., Antorrena, G., González-Álvarez, J., 2012. Response surface optimization of antioxidants extraction from chestnut (Castanea sativa) bur. Ind. Crops Prod. 35, 126-134. 


\section{Figure captions}

Figure 1 - Contour and response surface plots of TRC for methanol in function of temperature and solvent concentration (A); and temperature and extraction time (B).

Figure 2 - Contour and response surface plots of DPPH scavenging effect for methanol (A) and acetone (B), in function of temperature and solvent concentration (Time $=35$ $\min )$.

Figure 3 - Contour and response surface plots of DPPH scavenging effect for methanol (A) and acetone (B), in function of temperature and extraction time (Methanol and acetone at $30 \%(\mathrm{v} / \mathrm{v}))$.

Figure 4 - Combination of temperature and solvent concentration to obtain a TRC between 0.35 and $0.56 \mathrm{mg}$ GAE/g fresh weight and a DPPH scavenging effect between 80 and $90 \%$ for methanol extractions (A); and a TRC between 0.40 and $0.65 \mathrm{mg} \mathrm{GAE} / \mathrm{g}$ fresh weight and a DPPH scavenging effect between 80 and $90 \%$ for extractions with acetone (B). 
Table 1 - Independent variables and their coded and uncoded values for optimization.

\begin{tabular}{cccc}
\hline Coded value & $\begin{array}{c}\text { Solvent } \\
(\mathbf{\%}, \mathbf{v} / \mathbf{v})\end{array}$ & $\begin{array}{c}\text { Temperature } \\
\left({ }^{\circ} \mathbf{C}\right)\end{array}$ & $\begin{array}{c}\text { Time } \\
(\mathbf{m i n})\end{array}$ \\
\hline \multicolumn{5}{c}{ Methanol and Acetone } \\
\hline-1 & 30 & 30 & 10 \\
0 & 60 & 45 & 35 \\
1 & 90 & 60 & 60 \\
\hline-1 & -- & 30 & 10 \\
0 & -- & 45 & 35 \\
1 & -- & 60 & 60 \\
\hline
\end{tabular}


Table 2 - Central Composite Design with experimental and predicted values for total reducing capacity (TRC) (mg GAE/g fresh weight) and DPPH scavenging effect (\%) for methanol and acetone extractions.

\begin{tabular}{|c|c|c|c|c|c|c|c|c|c|c|c|}
\hline \multirow{3}{*}{ Experiment } & & & & \multicolumn{4}{|c|}{ Experimental values $\left(Y_{1}\right)^{\mathrm{a}}$} & \multicolumn{4}{|c|}{ Predicted values $\left(Y_{0}\right)$} \\
\hline & \multicolumn{3}{|c|}{ Levels of coded variables ${ }^{b}$} & \multicolumn{2}{|c|}{ Methanol } & \multicolumn{2}{|c|}{ Acetone } & \multicolumn{2}{|c|}{ Methanol } & \multicolumn{2}{|c|}{ Acetone } \\
\hline & $X_{1}$ & $X_{2}$ & $X_{3}$ & TRC $^{\mathrm{c}}$ & \% DPPH & TRC $^{\mathrm{c}}$ & \% DPPH & TRC $^{\mathrm{c}}$ & \% DPPH & TRC $^{\mathrm{c}}$ & \% DPPH \\
\hline 1 & 0 & 0 & 0 & 0.483 & 82.3 & 0.616 & 89.5 & 0.320 & 87.3 & 0.349 & 88.8 \\
\hline 2 & -1 & 1 & -1 & 0.566 & 81.4 & 0.669 & 77.8 & 0.509 & 81.2 & 0.567 & 77.0 \\
\hline 3 & 1 & -1 & -1 & 0.439 & 57.3 & 0.545 & 27.6 & 0.381 & 61.8 & 0.432 & 31.8 \\
\hline 4 & -1 & -1 & -1 & 0.298 & 87.8 & 0.287 & 85.8 & 0.335 & 85.0 & 0.391 & 80.8 \\
\hline 5 & 0 & 0 & 0 & 0.322 & 90.0 & 0.353 & 89.8 & 0.320 & 87.3 & 0.349 & 88.8 \\
\hline 6 & 0 & 0 & -1 & 0.330 & 90.5 & 0.385 & 88.5 & 0.372 & 90.8 & 0.411 & 91.0 \\
\hline 7 & 1 & 1 & 1 & 0.313 & 86.7 & 0.450 & 49.6 & 0.263 & 89.8 & 0.324 & 55.0 \\
\hline 8 & 1 & -1 & 1 & 0.344 & 51.4 & 0.264 & 10.4 & 0.389 & 51.9 & 0.344 & 11.6 \\
\hline 9 & -1 & 0 & 0 & 0.349 & 77.6 & 0.401 & 81.0 & 0.362 & 83.3 & 0.415 & 89.6 \\
\hline 10 & -1 & -1 & 1 & 0.336 & 72.4 & 0.404 & 69.4 & 0.291 & 74.2 & 0.297 & 70.5 \\
\hline 11 & 0 & -1 & 0 & 0.287 & 78.7 & 0.271 & 69.7 & 0.303 & 75.0 & 0.309 & 68.4 \\
\hline 12 & 0 & 0 & 1 & 0.332 & 89.4 & 0.298 & 88.5 & 0.332 & 88.5 & 0.360 & 84.7 \\
\hline 13 & 0 & 1 & 0 & 0.300 & 88.9 & 0.337 & 88.3 & 0.327 & 92.0 & 0.388 & 88.3 \\
\hline 14 & 0 & 0 & 0 & 0.290 & 82.6 & 0.311 & 87.1 & 0.320 & 87.3 & 0.349 & 88.8 \\
\hline 15 & 0 & 0 & 0 & 0.298 & 88.8 & 0.315 & 87.4 & 0.320 & 87.3 & 0.349 & 88.8 \\
\hline 16 & 1 & 1 & -1 & 0.269 & 85.0 & 0.246 & 58.0 & 0.299 & 83.5 & 0.332 & 57.2 \\
\hline 17 & 1 & 0 & 0 & 0.277 & 79.5 & 0.247 & 60.2 & 0.306 & 73.3 & 0.321 & 50.3 \\
\hline 18 & -1 & 1 & 1 & 0.375 & 90.8 & 0.462 & 88.5 & 0.421 & 86.6 & 0.554 & 84.6 \\
\hline 19 & 0 & 0 & 0 & 0.315 & 89.5 & 0.331 & 88.5 & 0.320 & 87.3 & 0.349 & 88.8 \\
\hline 20 & 0 & 0 & 0 & 0.302 & 89.4 & 0.342 & 87.8 & 0.320 & 87.3 & 0.349 & 88.8 \\
\hline
\end{tabular}

a Average of six values that resulted of three extractions evaluated in duplicate in terms of TRC and \%DPPH; ${ }^{\mathrm{b}} X_{1}-\mathrm{Solvent}$ concentration; $X_{2}-\mathrm{Temperature} ; X_{3}-\mathrm{Time} ;{ }^{\mathrm{c}} \mathrm{TRC}$

- Total Reducing Capacity, expressed in mg GAE/g fresh weight. 
Table 3 - Central Composite Design with experimental and predicted values for total reducing capacity (TRC) (mg GAE/g fresh weight) and DPPH scavenging effect (\%) for water extractions.

\begin{tabular}{ccccccc}
\hline \multirow{2}{*}{ Experiment } & \multicolumn{2}{c}{$\begin{array}{c}\text { Levels of coded } \\
\text { variables }^{\mathbf{a}}\end{array}$} & \multicolumn{2}{c}{$\begin{array}{c}\text { Experimental values } \\
\left(\boldsymbol{Y}_{\boldsymbol{1}} \mathbf{b}^{\mathbf{b}}\right.\end{array}$} & \multicolumn{2}{c}{$\begin{array}{c}\text { Predicted values } \\
\left(\boldsymbol{Y}_{\boldsymbol{0}}\right)\end{array}$} \\
\cline { 2 - 7 } & $\boldsymbol{X}_{\boldsymbol{1}}$ & $\boldsymbol{X}_{\mathbf{2}}$ & $\mathbf{T R C}^{\mathbf{c}}$ & \% DPPH & TRC $^{\mathbf{c}}$ & \% DPPH \\
\hline 1 & 0 & 0 & 0.586 & 71.7 & 0.540 & 75.7 \\
2 & -1 & 1 & 0.356 & 81.9 & 0.316 & 81.3 \\
3 & 1 & -1 & 0.365 & 81.1 & 0.354 & 83.0 \\
4 & -1 & -1 & 0.337 & 67.0 & 0.316 & 70.7 \\
5 & 0 & 0 & 0.727 & 64.0 & 0.540 & 75.7 \\
6 & 0 & 0 & 0.741 & 63.2 & 0.540 & 75.7 \\
7 & 1 & 0 & 0.420 & 79.0 & 0.463 & 79.5 \\
8 & -1 & 0 & 0.345 & 79.5 & 0.407 & 76.4 \\
9 & 0 & -1 & 0.405 & 80.2 & 0.440 & 74.6 \\
10 & 1 & 1 & 0.420 & 77.8 & 0.390 & 75.4 \\
11 & 0 & 1 & 0.387 & 73.2 & 0.458 & 76.2 \\
12 & 0 & 0 & 0.382 & 89.4 & 0.540 & 75.7 \\
13 & 0 & 0 & 0.366 & 87.8 & 0.540 & 75.7 \\
\hline
\end{tabular}

${ }^{\mathrm{a}} X_{1}$ - Temperature; $X_{2}$ - Time; ${ }^{\mathrm{b}}$ Average of six values that resulted of three extractions evaluated in duplicate in terms of TRC and \%DPPH; ${ }^{\mathrm{C}} \mathrm{TRC}$ - Total Reducing Capacity, expressed in mg GAE/g fresh weight. 
Table 4 - p-values and $R^{2}$ determined for the models obtained for Total Reducing Capacity (TRC) and DPPH scavenging effect for methanol, acetone and water.

\begin{tabular}{|c|c|c|c|c|c|c|c|c|c|c|c|c|}
\hline \multirow{3}{*}{ Term } & \multicolumn{4}{|c|}{ Methanol } & \multicolumn{4}{|c|}{ Acetone } & \multicolumn{4}{|c|}{ Water } \\
\hline & TRC & TRC & $\% \mathrm{DPPH}$ & $\% \mathrm{DPPH}$ & TRC & TRC & $\% \mathrm{DPPH}$ & DPPH & TRC & TRC & $\% \mathrm{DPPH}$ & DPPH \\
\hline & Coefficient & $p$ & Coefficient & $p$ & Coefficient & $p$ & Coefficient & $p$ & Coefficient & $p$ & Coefficient & $p$ \\
\hline Constant & 0.320 & 0.000 & 87.32 & 0.000 & 0.3486 & 0.000 & 88.78 & 0.000 & 0.540 & 0.000 & 75.74 & 0.000 \\
\hline$X_{1}$ & -0.028 & 0.234 & -5.01 & 0.007 & -0.0471 & 0.283 & -19.66 & 0.000 & 0.028 & 0.653 & 1.58 & 0.713 \\
\hline$X_{2}$ & 0.012 & 0.605 & 8.52 & 0.000 & 0.0393 & 0.366 & 9.91 & 0.000 & 0.009 & 0.879 & 0.77 & 0.858 \\
\hline$X_{3}$ & -0.020 & 0.386 & -1.13 & 0.466 & -0.0254 & 0.554 & -3.13 & 0.097 & -- & -- & -- & -- \\
\hline$X_{l}^{2}$ & 0.014 & 0.742 & -9.10 & 0.010 & 0.0196 & 0.809 & -18.84 & 0.000 & -0.105 & 0.270 & 2.20 & 0.728 \\
\hline$X_{2}^{2}$ & -0.005 & 0.906 & -3.84 & 0.206 & -0.0004 & 0.996 & -10.43 & 0.010 & -0.091 & 0.331 & -0.34 & 0.956 \\
\hline$X_{3}^{2}$ & 0.032 & 0.464 & 2.30 & 0.437 & 0.0371 & 0.649 & -0.96 & 0.774 & & -- & -- & -- \\
\hline$X_{1} X_{2}$ & -0.064 & 0.029 & 6.38 & 0.003 & -0.0691 & 0.167 & 7.32 & 0.003 & 0.009 & 0.905 & -4.55 & 0.398 \\
\hline$X_{1} X_{3}$ & 0.013 & 0.620 & 0.22 & 0.895 & 0.0016 & 0.973 & -2.47 & 0.225 & & -- & -- & -- \\
\hline$X_{2} X_{3}$ & -0.011 & 0.661 & 4.05 & 0.036 & 0.0201 & 0.674 & 4.49 & 0.041 & & -- & -- & -- \\
\hline Lack of fit & & 0.574 & & 0.181 & & 0.337 & & 0.000 & & 0.908 & & 0.921 \\
\hline$R^{2}=$ & 0.529 & & 0.900 & & 0.364 & & 0.969 & & 0.382 & & 0.139 & \\
\hline
\end{tabular}



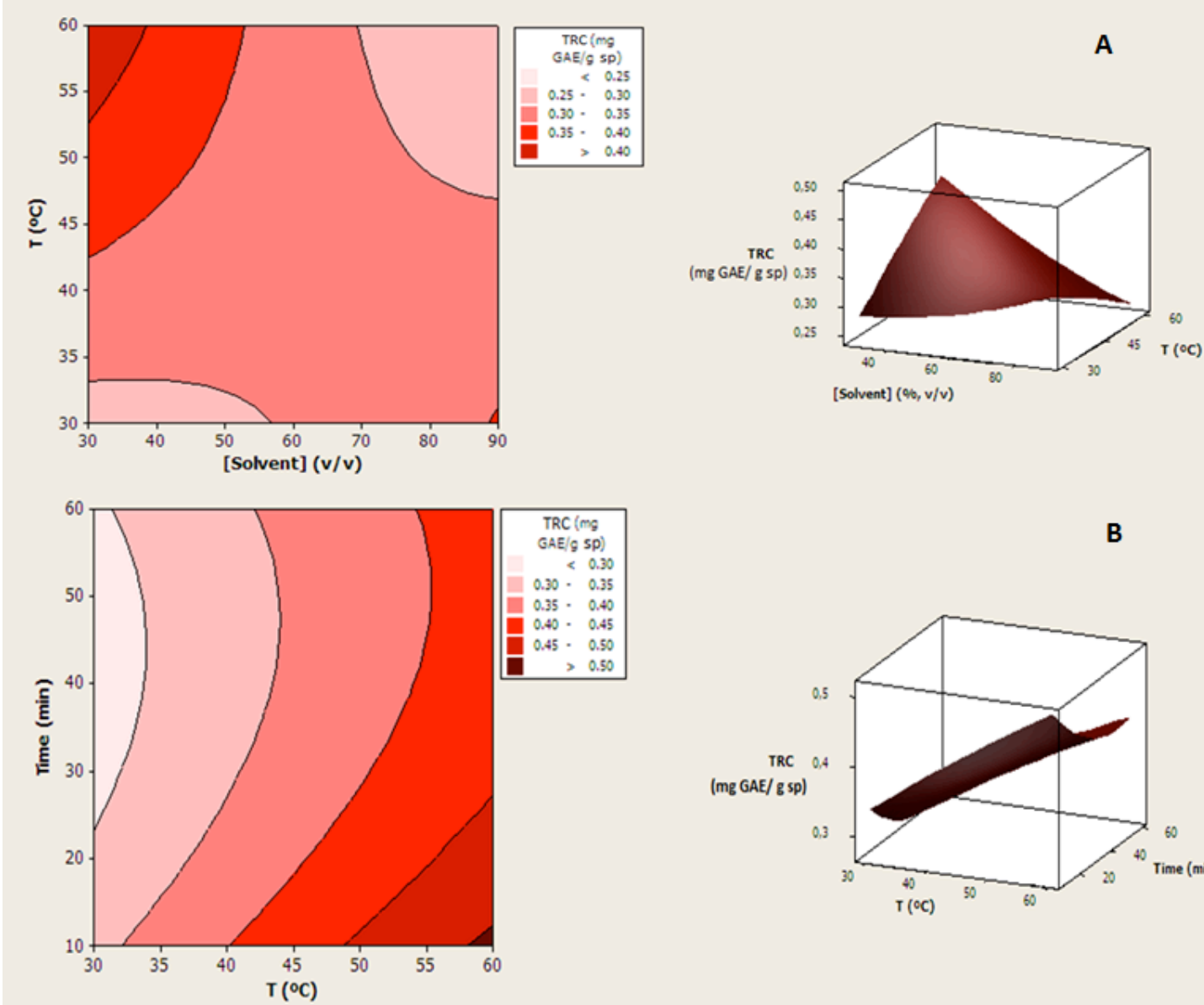

B

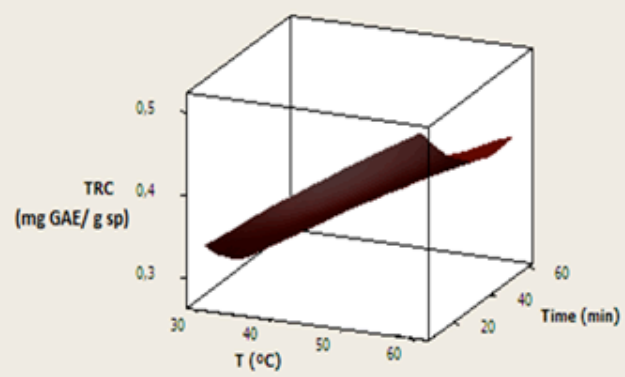

Figure 1 

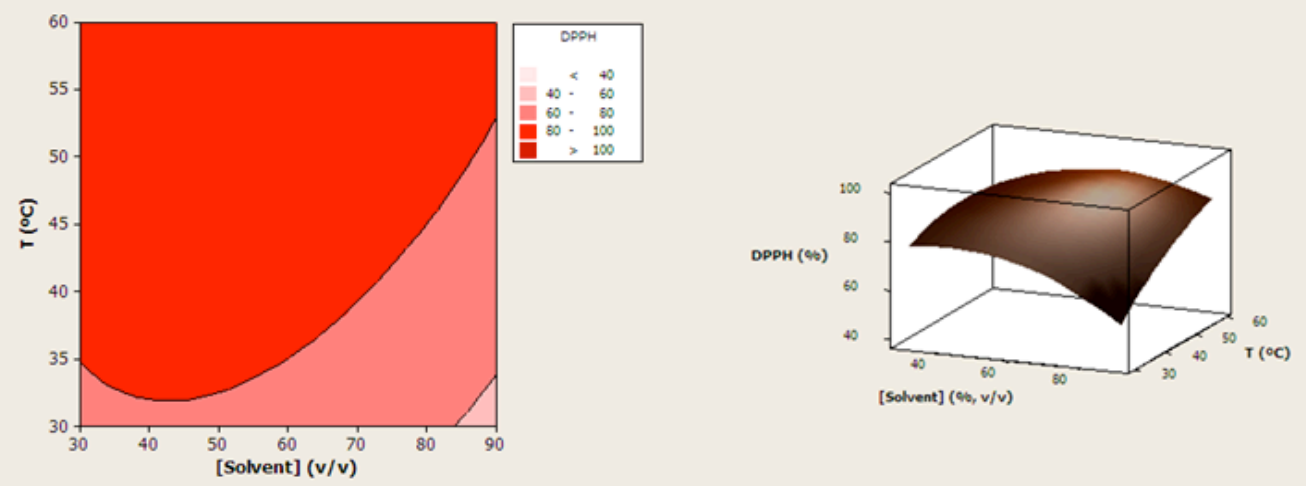

A

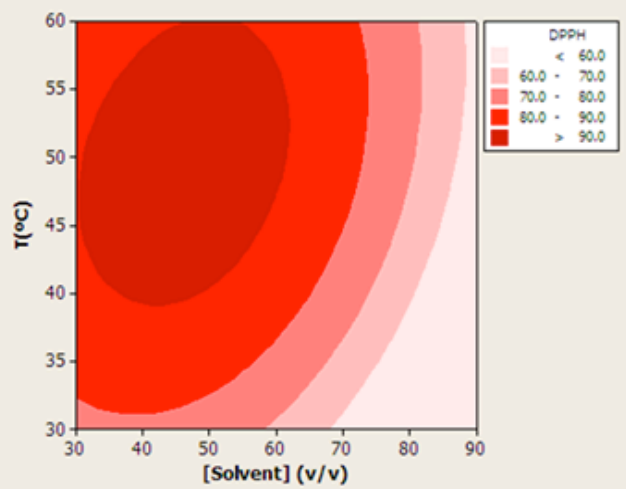

B

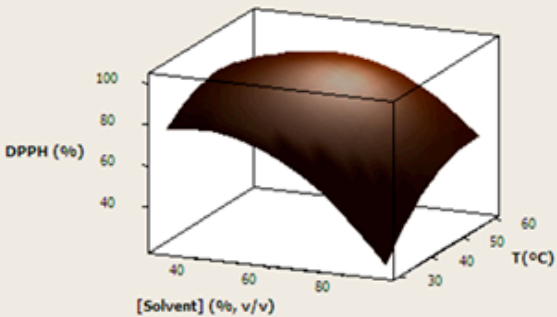

Figure 2 

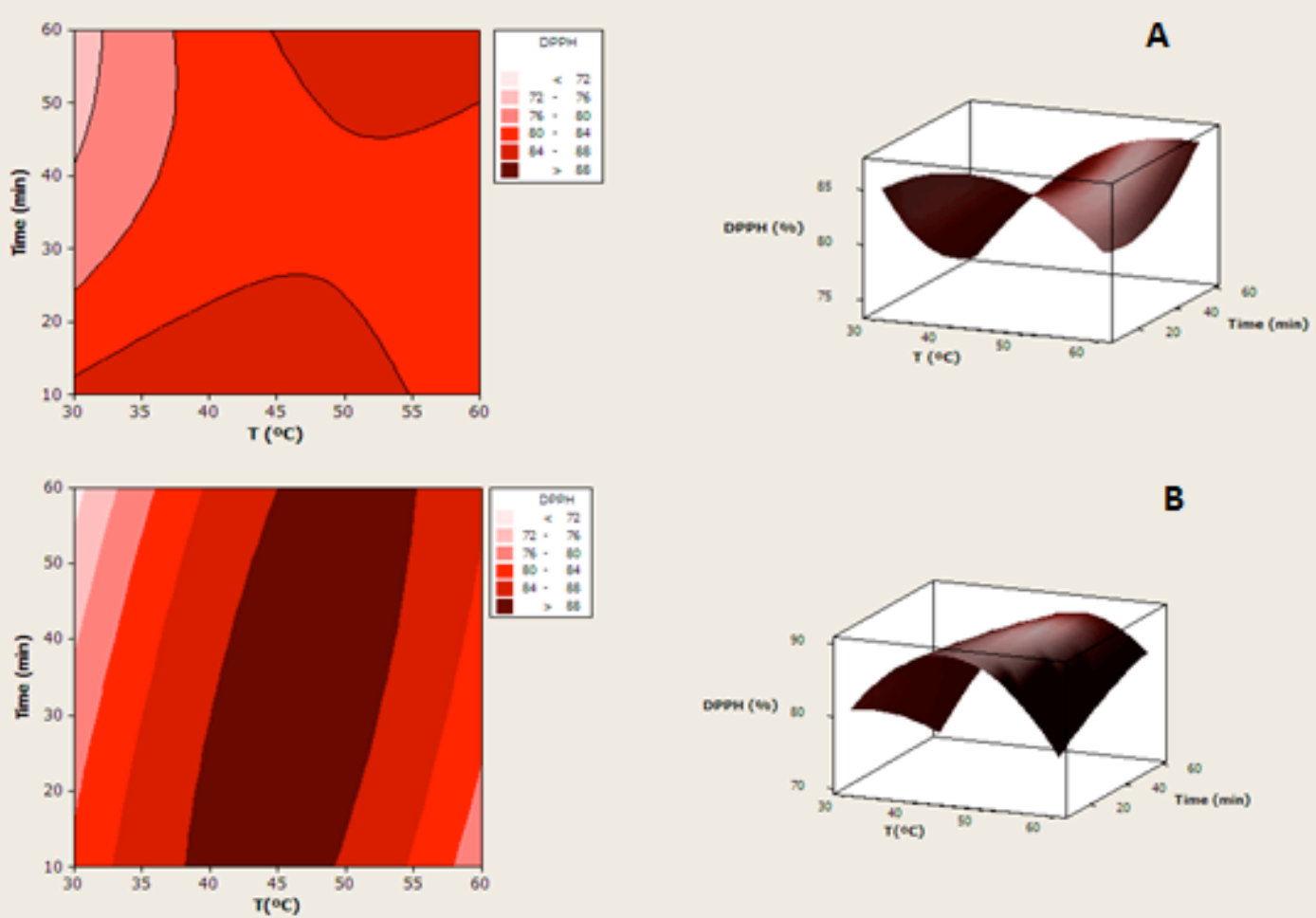

B

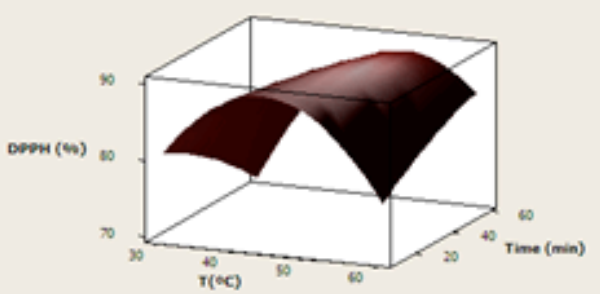

Figure 3 

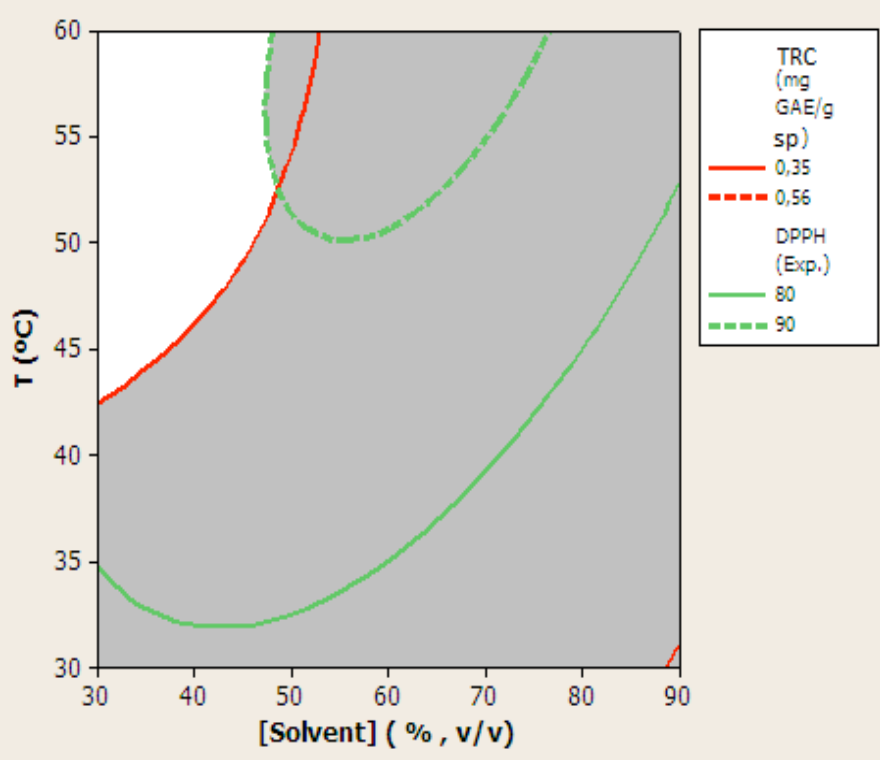

A

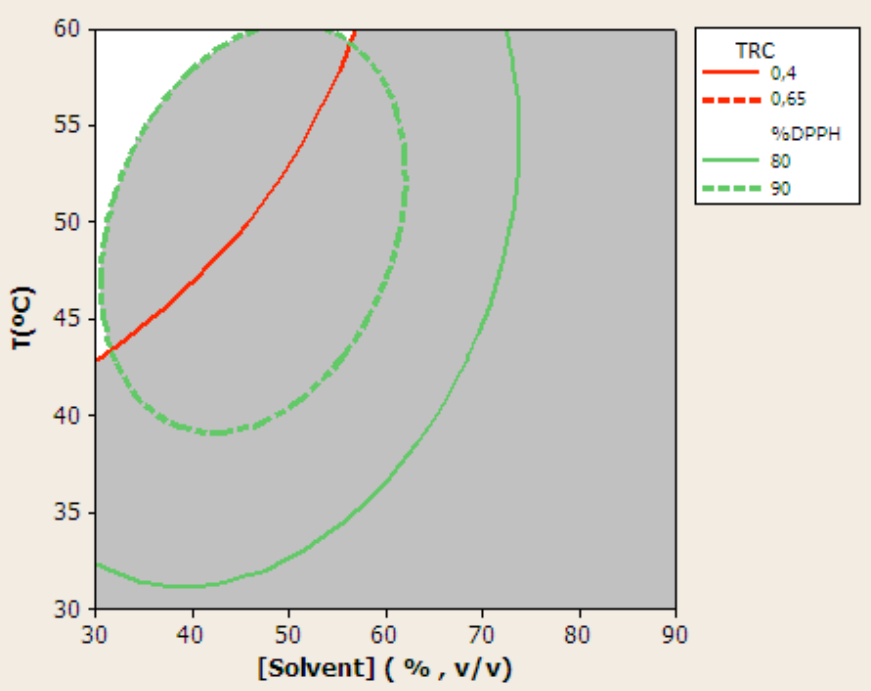

B

Figure 4 